\title{
Empirical Test of the Dividend Discount Model's Forecasting Power
}

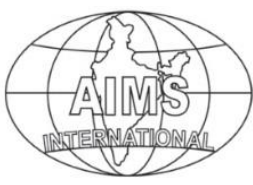

DOI: $10.26573 / 2020.14 .1 .1$

Volume 14, Number 1

January 2020, pp. 1- 10

\author{
Rahul Verma \\ University of Houston-Downtown \\ Houston, USA \\ (vermar@uhd.edu)
}

The purpose of this research is to empirically test the forecasting power of a well-known asset valuation model, the dividend discount model. It examines if there exists a significant pricing errors (undervaluation/overvaluation in stock prices) by estimating the difference between intrinsic values predicted by this model and realized returns at varied expected growth rate in dividends. The results suggest that there exist significant differences between the returns forecasted by the dividend discount model and the realized returns. These evidences of pricing errors generated by a rational asset pricing valuation model suggest the role of investors' irrationality or noise as an additional factor which seems to be priced in the market. An existence of such pricing errors validates the usefulness of fundamental analysis to identify undervaluation and overvaluation in asset prices.

Keywords: Mispricing, Dividend Discount Model, Behavioral Biases

\section{Introduction}

The recent stock market sell-off due to Covid-19 (during March 2020) raises an important question on whether there exists a systematic mispricing in asset prices. Fear observed in the market is unprecedented and an extreme reaction to a major shock is understandable. The economy is expected to take a big hit and it is no surprise that the valuations have readjusted downwardly. However, what is surprising is an extremely high volatility during a short period of time. Trading periods of extreme pessimisms are followed by high bullishness and that has created confusion in the minds of ordinary investors. The volatility index which was at a level of around 20 before this medical crisis suddenly jumped 4 times to 80 s and then again fell to 60s. In a two weeks period there were days when the Dow Jones Industrial Average fell by over $12 \%$ and then immediately went up by almost $10 \%$. It is difficult to understand the reason behind such a high volatility and simultaneously high bullishness and bearishness during a such a short time period.

It is highly unlikely that any rational asset pricing model could have predicted such a severe downturn during such unprecedented times. However, it brings us back to the question on whether stock prices truly reflect the today's value of expected cash flows even during normal times when the volatility is low and there is no major unanticipated shock. Are stock prices justified by the economic fundamental or there 
is a role of noise traders? Can standard asset pricing models in which rational investors always force stock prices to be equal to their intrinsic values predict expected returns to a reasonable degree? If the rational asset pricing models are unable to predict the stock returns then it would mean an existence of pricing errors due to irrational behavior of investors or noise trading. The purpose of this research is to empirically test the forecasting power of a well-known asset valuation model, the dividend discount model. Specifically, it examines if there exists a significant pricing errors (undervaluation/overvaluation) by comparing intrinsic values predicted by this model and the realized returns at varied expected growth rates in dividends.

Any evidence of pricing error generated by rational asset pricing valuation models would signal the role of investors' irrationality or noise as an additional factor which are priced in the market. It would lend support to the theories of behavioral finance. Such empirical test is the main contribution of this study. Accordingly, this study extends prior research by investigating the following research questions: (i) whether a systematic pricing error exists in the overall stock market (ii) what is the magnitude of the pricing error (if any) during the sample period? (iii) are there significant differences in pricing errors at varied expected growth rates in dividends?

The dividend discount model is estimated to compute the expected returns for the S\&P 500 over a sample period of 1988-2019 on a monthly basis. This expected return is computed for three different expected growth rates in dividends based on $\mathrm{P} / \mathrm{E}$ ratio, dividend yield and earnings per shares of S\&P 500. The results suggest the following: (i) there existing significant differences between the returns forecasted by the dividend discount model and the realized returns during the sample period (ii) the mean magnitude of the pricing errors is approximately $2.7 \%$ on a monthly basis (iii) the pricing errors are persistent and there are insignificant differences in pricing errors at varied expected growth rates in dividends.

These results can have important implications for investors while devising their trading strategies. It means that in addition to risk factors, investors should consider the role of irrational behavior of investors which can have sustained effect on stock valuation. A direct implication of these results is that conventional measures of temporal variation in risk omit an important source of risk: noise. An existence of such pricing errors validates the usefulness of fundamental analysis in which investors tends to identify undervaluation and overvaluation in asset prices. This research argues that an ability to predict market errors in addition to expected returns is important in tactical asset allocation decisions.

The remainder of this paper is organized as follows: Section two reviews the existing literature on noise trading while section three presents the model. Section four presents the data and section five presents empirical findings. Section six concludes.

\section{Literature Review}

Studies suggest that the traditional asset pricing models which are rooted in full rationality may not be to capture the role of a large group of investors with cognitive biases which could cause stock prices to deviate from their intrinsic values. In recent years there has been a growing debate on the possible linkages between the behavioral aspects of such investors and stock prices. The financial economics have become more receptive to imperfect rational explanations and in this regard, 
behavioral finance has emerged as a major determinant of stock prices ${ }^{1}$. Under this approach, the central task is to examine how stock prices are related not only to risks, but also to the noise (Hirshleifer, 2001). After decades of study, the sources of risk premium in purely rational dynamic models are well understood; while, dynamic psychology-based asset pricing theories are still in the infancy stage. This debate surrounding asset pricing has identified two prime suspects in setting stock prices: fundamentals and noise (Statman, 2019).

Stock prices are determined by the two types of investors: rational investors, free of behavioral biases and noise traders, susceptible to cognitive and emotional errors. Asset prices equal their intrinsic values in markets where all investors are rational. But pricing errors exists in markets where quasi-rational investors steer prices in directions corresponding to their sentiment and the forces of arbitrage are too weak.

Most notable for this paper is the research of DeLong, Shleifer, Summers, and Waldmann (DSSW) (1990). Noise trader models in finance imply that subsets of investors often do not make investment decisions based on a company's fundamentals and are capable of affecting stock prices by way of unpredictable changes in their sentiments. The impact of noise trading as suggested by DSSW (1990) is due to the interaction of the following four effects of irrationality on stock returns and volatility: (i) trading by bullish or bearish investors which takes the price away from the fundamental value, (ii) adjustment in the market risk due to the changes in noise traders' demand of stocks based on their sentiments, (iii) fluctuations in stock prices due to the variations of noise traders' misperceptions about the risk, (iv) deviations of stock prices from its fundamental value due to the fact that the average misperceptions of noise traders associated with shifts in sentiments is not zero. The first two effects capture the short-run while the last two effects capture the long run impact of noise trading on asset prices.

Among recent studies, Weber (2018) find that the degree of mispricing systematically varies with investor sentiment. In times of high investor sentiment, optimistic investors bid up prices of short-sale constrained, high duration stocks. Den (2019) and Guidol in and Ricci (2019) find linkages between investor sentiment and mispricing in China and European markets respectively. Cornell et al., (2017) find that mispricing is low when accounting quality is high. Avramov et al., (2019) find mispricing in distressed stock and bond markets during high sentiment periods while Ryu and Wang (2020) find evidence of mispricing in the derivative markets. An empirical test of the forecasting power of a rational asset pricing model would contribute to this ongoing debate and shed new light on the issue of investors' irrationality.

${ }^{1}$ The theoretical framework describing the role investor sentiments play in determining stock prices is provided by researchers such as Black (1986), Trueman (1988), DSSW (1990), Shleifer and Summers (1990), Lakonishok et al. (1991), Campbell and Kyle (1993), Shefrin and Statman (1994), Palomino (1996), Daniel et al.(1998) and Hong and Stein (1999); brown and Cliff(2004; 2005). A direct implication of these studies is certain groups of investors (noise traders) who often do not make investment decisions based on a company's fundamentals are capable of affecting stock prices by way of unpredictable changes in their sentiments. 


\section{Model Specification}

The dividend discount model developed by Gordon and Shapiro (1956) and Gordon (1959) remains a useful tool for estimating the value of a firm. When an investor buys stock, he/she expects to get two types of cash flows - dividends over the holding period and an expected price at the end of the holding period. Since this expected price is itself determined by future dividends, the value of a stock is the present value of dividends through infinity. The rationale for the model lies in the present value rule - the value of any asset is the present value of expected future cash flows discounted at a rate appropriate to the riskiness of the cash flows.

The dividend discount model implies that in the case of constant expected growth of dividends $(g)$, the expected rate of price appreciation in any year will equal that constant rate, $g$. For a stock whose market price $\left(P_{0}\right)$ is assumed to equal its intrinsic value $\left(V_{0}\right)$ the expected return $(k)$ will be given by the following discounted cash flow (DCF) formula:

$k=E\left(D_{1}\right) / P_{o}+g$

Where $\mathrm{E}\left(D_{l}\right)$ is the expected dividend per share in the next period. This formula offers a means to infer the market capitalization rate of a stock.

There are two basic inputs to the model - expected growth rate in dividends and the cost on equity. To obtain the expected growth rate in dividends, we make assumptions about expected future growth rates in earnings and payout ratios. The required rate of return on a stock is determined by its riskiness, measured differently in different models - the market beta in the Capital Asset Pricing Model (CAPM), and the factor betas in the arbitrage and multi-factor models. The model is flexible enough to allow for time-varying discount rates, where the time variation is caused by expected changes in interest rates or risk across time.

Accordingly, in the constant growth model, a company's historical average dividend or earnings growth rate is frequently taken as an estimate of future dividend or earnings growth. In general, if $E P S_{0}$ is the earliest earnings per share and $E P S_{N}$ is the latest earnings per share in the $N^{\text {th }}$ year, the growth rate can be calculated as:

$g=\left(E P S_{N} / E P S_{0}\right)^{1 / N}-1$

Therefore, by observing the expected dividend yield and estimating the growth rate of dividends, we can compute expected return $(k)$ as sum of expected dividends yields and expected growth rate in dividends:

$k=D_{0} *(1+g) / P_{0}+g$

Where, $D_{0}$ is the current dividend which is observable. However, the actual holding period return $\left(k^{*}\right)$ calculated as the log first difference of actual stock prices during the period $t$ and $t-1$ may not be equal to the calculated $k$ (expected return based on the model). In that case, $\mathrm{P}_{0} \neq \mathrm{V}_{0}$ and would generate a pricing error $\left(p^{e}\right)$ which will be equal to the difference between the realized return and the expected return based on DCF approach:

$p^{e}=k^{*}-k$ 


\section{Data and Descriptive Statistics}

The following data is obtained in monthly frequency from January 1988 to August 2019. In order to develop the pricing error variable, the following data series are obtained from the Global Insight Database: (i) S\&P 500 common stock price index (code: FSPCOM) (ii) S\&P 500 common stock dividend yield (code: FSDXP) and (iii) S\&P 500 commons stock: Price-Earnings ratio (code: FSPXE). The pricing error variable is developed in accordance with equation (4). It is the difference between the actual holding period return and the expected return (i.e., $p^{e}=k^{*}-k$ ). The actual holding period return $\left(k^{*}\right)$ is calculated by computing the continuously compounded returns of S\&P 500 stock price index values.

In order to compute the expected return $(k)$ the following steps are employed: first, the earnings for S\&P 500 index is computed based on the relationship EPS = Price /(P-E ratio) i.e., by dividing the S\&P 500 index level with the S\&P 500 PriceEarnings ratio. Second, using equation (2), the expected growth rate (annualized) in earnings is computed for different values of N. Specifically, 1 year, 2 years and 3 years annual expected growth rates in earnings are computed. Finally, in accordance with equation (3), the expected return is computed by adding the S\&P 500 dividend yield to different expected annual growth rates in earnings.

Table 1 reports the descriptive statistics of the data. The mean of monthly returns of the S\&P 500 is approximately $0.71 \%$ (annualized 8.52\%) and shows a high volatility of $3.57 \%$ (approximately $43 \%$ annualized). The maximum and minimum monthly returns of S\&P 500 are approximately $13 \%$ and $-23 \%$ respectively. The average dividends yield of the overall market is approximately $2.2 \%$ and has fluctuated between $1 \%-4 \%$ during the sample period. In this current low interest rate environment, such dividend yield seems very attractive. The average market multiple (P/E ratio) is approximately 23 times representing earnings yield of $4.35 \%$. An extremely high $\mathrm{P} / \mathrm{E}$ ratio of 135 during early 2009, suggests market expectations of extremely high growth during the post financial crisis period. The average earnings per share is $\$ 57$ with a minimum and maximum values of $\$ 7$ and $\$ 142$ respectively, suggesting varied corporate earnings during the sample period.

Table 1 Descriptive Statistics

\begin{tabular}{|l|c|c|c|c|}
\hline & SP500 & SP_DIV & SP_PE & EPS \\
\hline Mean & 0.0071 & 0.0217 & 22.9195 & 56.7308 \\
\hline Median & 0.0102 & 0.0197 & 20.6600 & 48.0083 \\
\hline Maximum & 0.1305 & 0.0401 & 134.6900 & 141.7559 \\
\hline Minimum & -0.2281 & 0.0109 & 12.0700 & 6.9480 \\
\hline Standard Deviation & 0.0357 & 0.0066 & 12.5637 & 33.5129 \\
\hline Kurtosis & 6.3291 & 0.0002 & 49.0568 & -0.7082 \\
\hline Skewness & -1.0357 & 0.8376 & 6.2886 & 0.5990 \\
\hline
\end{tabular}

The variables are S\&P 500 index returns (SP500), S\&P 500 dividend yield (SP_DIV), S\&P 500 Price to Earnings Multiple (SP_PE), estimated earnings of S\&P 500 (EPS). 


\section{Estimation Results}

The first step is to generate a series of expected earnings per share for S\&P 500. This is calculated by dividing the monthly S\&P 500 index values with its corresponding $\mathrm{P} / \mathrm{E}$ ratio. Based on this earnings variable, three different series of expected annual growth rate in earnings (equation 2) is computed for three separate periods: 12 months, 24 months and 36 months. Table 2 reports the mean of expected growth rates in earnings corresponding to these three periods. The mean of expected growth rates in S\&P 500 earnings is approximately $6 \%$ for all these periods $(6.25 \%, 5.99 \%$ and $6.15 \%$ for 1,2 and 3 years respectively). In order to test if these three expected growth rates in earnings are significantly different from zero, $t$-tests are performed. The null hypothesis of growth rate in earnings equal to zero is rejected at $1 \%$ significance level in all the three cases.

The second step is to compute the expected returns in accordance with equation (3) i.e., based on the S\&P 500 dividend yield and the expected growth rate in earnings computed above. Accordingly, for the three periods, three separate series of expected returns are generated. The mean of these series and $t$-statistics are reported in table 2. The mean expected returns are $8.44 \%, 8.12 \%$ and $8.20 \%$ for 12,24 and 36 months respectively. The $t$-tests suggests that these three values are significantly different from zero.

The next step is to compute the pricing error, in accordance with equation (4) i.e., the difference between the realized S\&P 500 returns and the expected returns generated from equation (3) or, from the dividend discount model. Specifically, the 1 year, 2 years and 3 years pricing errors are generated based on three expected returns and projected growth rates in dividends. Three separate values for the expected growth rate in dividends are computed for different values of $\mathrm{N}$ in equation (2). The mean of these pricing error variables and $t$-test results of these values are presented in table 2. The pricing error seems to be consistent across these three growth rate periods. The mean of pricing error for 12 months period is approximately $2.48 \%$ and significant at $10 \%$ level. The corresponding figure for 2 years and 3 years period is approximately $2.8 \%$ and significant at $1 \%$ level.

Overall, the evidence suggests that significant and systematic pricing error does exist in the U.S. market. Specifically, the magnitude of the difference between the expected returns generated by the dividend discount model and realized returns is almost $2.7 \%$ (average of $2.48 \%, 2.84 \%$ and $2.83 \%$ ). This is consistent with Weber (2018) which find a spread of $2.51 \%$ per month by using cash flow data from the balance sheets.

Table 2 Expected Growth Rate in Dividends, Expected Returns and Pricing Errors

\begin{tabular}{|c|c|c|c|}
\hline & N= 12 months & N= 24 months & N= 36 months \\
\hline$g$ & $0.0625 * * *(3.49)$ & $0.0599 * * *(4.27)$ & $0.0615 * * *(5.49)$ \\
\hline$k$ & $0.0844 * * *(4.73)$ & $0.0812 * * *(5.82)$ & $0.0820 * * *(7.37)$ \\
\hline$p^{e}$ & $0.0248 *(1.76)$ & $0.0284 * *(2.29)$ & $0.0283 * * *(2.47)$ \\
\hline
\end{tabular}

The variables are expected growth rate in dividends $(\mathrm{g})$, expected returns based on the dividend valuation model $(\mathrm{k})$, pricing errors $\left(\mathrm{p}^{\mathrm{e}}\right)$. *, ** and *** represent significance at $10 \%, 5 \%$ and $1 \%$ respectively. T-statistics are in parentheses. 


\section{Pricing Errors based on 1 Year Growth Rate}

2.0000

0.0000

$-2.0000$

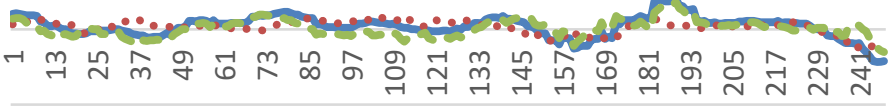

Forecasted $\quad . .$. Actual $\quad-0$ Pricing Errors

\section{Pricing Errors based on 2 Year Growth}

\section{Rate}

1.0000

0.0000

$\neg \stackrel{\sim}{\sim}$ m

$-1.0000$

Forecasted $\quad$..... Actual $-\infty$ Pricing Errors

\section{Pricing Errors based on 3 Year Growth} Rates

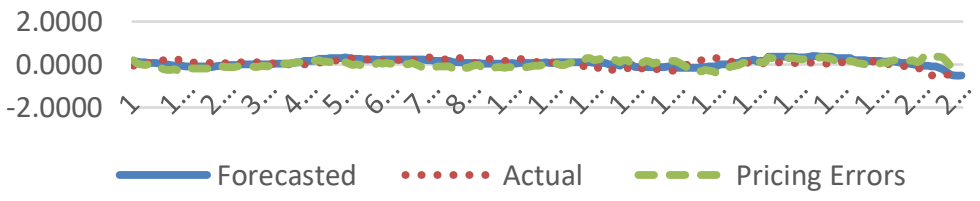

Figure 1 Expected Returns, Realized Returns and Pricing Errors at Multiple Growth Rates

The plots of expected returns generated by the dividend valuation model, the realized returns and the corresponding pricing errors for the three scenarios are reported in Figure 1. The forecasted series of expected returns based 1 and 2 years expected growth rate in earnings seems to show similar trend. The corresponding pricing error variables based on these two expected growth rates therefore also have almost similar path. However, in comparison, the expected returns and the pricing error series for $\mathrm{N}=36$ are flatter. These figures suggest that there could be some differences in the pricing errors based on the expected growth rate in earnings. 
Therefore, it is important to investigate if difference between expected and realized returns are affected by the periods chosen to compute expected growth rate in earnings. Accordingly, $t$-tests are conducted to check the if the difference in the means of these pricing errors are significantly different from zero. It is important to conduct such test on whether the pricing errors at different growth rates are significantly different since expected growth rates generated by different periods has led to different pricing errors. Specifically, the pricing errors for $\mathrm{N}=12$ and $\mathrm{N}=24$ or 36 months are $2.48 \%, 2.84 \%$ and $2.83 \%$ respectively.

Table 3 reports the results of the $t$-tests for difference in means of pricing errors for different expected growth rates. The difference in mean between 1- and 2-years growth induced pricing errors is approximately $0.8 \%$. The differences in means between pricing errors in the other two cases are smaller (approximately $0.2 \%$ ). In all these three cases, low $t$-statistics fails to reject the null hypothesis of difference in means equal to zero. This test indicates that the period chosen to compute the expected growth rate in earnings has insignificant effect on the dividend valuation model's pricing errors. This result is consistent with the view that there is a systematic mispricing in the U.S. stock market based on the traditional asset pricing model.

Overall, the empirical results are consistent with existing empirical studies on pricing errors which find evidence of systematic and persistent mispricing in the stocks, bonds, derivatives and international markets (Weber, 2018, Den, 2019, Cornell et al., 2017, Ryu and Wang, Avramov et al., 2019, Guidol in and Ricci, 2019).

Table 3 Test of Equality in means of Pricing Errors for Different Expected Growth Rates

\begin{tabular}{|c|c|c|c|}
\hline & $\begin{array}{c}\mathbf{N}=12 \text { and } \\
\mathbf{N = 2 4} \text { months }\end{array}$ & $\begin{array}{c}\mathbf{N = 1 2} \text { and } \\
\mathbf{N = 3 6} \text { months }\end{array}$ & $\begin{array}{c}\mathbf{N = 2 4} \text { and } \\
\mathbf{N = 3 6} \text { months }\end{array}$ \\
\hline \multirow{2}{*}{$\Delta p^{e}$} & $\begin{array}{c}0.0081 \\
(0.7776)\end{array}$ & $\begin{array}{c}0.0025 \\
(0.8678)\end{array}$ & $\begin{array}{c}0.0026 \\
(0.7333)\end{array}$ \\
\hline
\end{tabular}

The variable is difference in means of pricing errors $\left(\Delta p^{e}\right)^{*}, * *$ and $* * *$ represent significance at $10 \%, 5 \%$ and $1 \%$ respectively. T-statistics are in parentheses.

\section{Conclusion}

In this paper, the dividend discount model is estimated to compute the expected returns for the S\&P 500 and compared with realized returns over a period of 19882019. The following research questions are investigated: (i) whether a systematic pricing error exists in the overall stock market (ii) what is the magnitude of the pricing errors (if any) during the sample period? (iii) are there significant differences in pricing errors at different growth rates in dividends? The results suggest the following: (i) there existing significant differences between the returns forecasted by the dividend discount model and the realized returns during the sample period (ii) the mean magnitude of the pricing errors is approximately $2.7 \%$ on a monthly basis (iii) the pricing errors are persistent and there are insignificant differences in pricing errors at different expected growth rates in dividends. These evidences of pricing error generated by rational asset pricing valuation model indicate the role of 
investors' irrationality or noise as an additional factor which seems to be priced in the market. It lends support to the theories of behavioral finance.

These results can have important implications for investors while devising their trading strategies. In addition to risk factors, one can also consider the role of irrational behavior of investors which can have sustained effect on pricing errors. A direct implication of these results is that conventional measures of temporal variation in risk omit an important source of risk: noise. An existence of such pricing errors based on a traditional asset pricing model validate the usefulness of fundamental analysis in which investors identifies undervaluation and overvaluation in asset prices.

This research argues that an ability to predict market errors in addition to expected returns is important in tactical asset allocation decisions. Quasi-rational sentiments are often the main driver of deviations of stock prices from their true values, particularly during times of extreme volatility. During such times, a typical investor looking at economic fundamentals to guide buy or sell decisions has the wrong information set and would be better guided by looking at investors' irrationality as the main driver; one would want to analyze how market participants are reacting to noise.

The future research can focus on investigating the determinant of the pricing errors in the financial markets. Specifically, empirical examinations of relationship between mispricing and investors' irrational behavior could be a good enhancement in this area. Currently, such investigation remains contentious due to the absence of precise valuation models which could measure deviations*.

\section{References}

1. Avramov, D., Chordia, T., Jostova, G. \& Philipov, A., 'Bonds, stocks, and sources of mispricing', George Mason University School of Business Research Paper, 2019 No. 18-5.

2. Black, F., 'Noise', Journal of Finance, 41, 3, 1986, 529-543.

3. Brown, G.W. \& Cliff, M.T., 'Investor sentiment and the near-term stock market', Journal of Empirical Finance, 11, 2004, 1-27.

4. Brown, G.W. \&Cliff, M.T., 'Investor sentiment and asset valuation', Journal of Business, Volume 78, 2005, Number 2, 405-440

5. Clarke, R.G. \& Statman, M., 'Bullish or bearish?', Financial Analysts Journal, May/June, 1998, 63-72.

6. Campbell, J.Y. \& A.S. Kyle., 'Smart Money, Noise Trading, and Stock Price Behavior', Review of Economic Studies, 1993, 60. 1-34.

7. Cornell, B., Wayne R. Landsman \&Stephen R. Stubben., 'Accounting Information, Investor Sentiment, and Market Pricing', Journal of Law, Finance, and Accounting, Vol. 2, 2017, 325-345.

*This research was supported by the ORCA award fund from the University of Houston-Downtown. 
8. Daniel, K., D. Hirshleifer, \& Subrahmanyam, A., 'Investor Psychology and Security Market Under and Overreactions', Journal of Finance, 53, 1998, 18391886.

9. DeLong, Shleifer, J., Summers, A. \& Waldmann, R., 'Noise trader risk in financial markets', Journal of Political Economy 98, 1990, 703-738.

10. Den, Y., Investor Sentiment and Mispricing of Assets-from Behavioral Finance Perspective', the Frontiers of Society, Science and Technology, 2019, Vol 1 (7), 44-51.

11. Gordon, M.J. \& Shapiro, E., 'Capital Equipment Analysis: The Required Rate of Profit', Management Science, 3, (1), 1956, 102-110. Reprinted in Management of Corporate Capital, 1959.

12. Gordon, Myron J., 'Dividends, Earnings and Stock Prices', Review of Economics and Statistics, 41, 1959, (2): 99-105.

13. Guidolin, M., and Ricci, A., 'Arbitrage risk and a sentiment as causes of persistent mispricing: The European evidence', The Quarterly Review of Economics and Finance, 2019, (forthcoming).

14. Hirshleifer, D., 'Investor psychology and asset pricing' Journal of Finance, 56, 2001, 1533-1597.

15. Lakonishok, J., A. Shleifer \&R. W. Vishny., 'The Impact of Institutional Trading on Stock Prices', Journal of Financial Economics 32, 1992,23 - 43.

16. Palomino, F., 'Noise Trading in Small Markets' Journal of Finance, 51, 1996,4, $1537-1550$

17. Ryu, D., and Yang, H., 'Noise traders, mispricing, and price adjustments in derivatives markets', The European Journal of Finance, 26:6, 2020,480-499.

18. Shleifer, A. Summers, L., 'The noise trader approach to finance", Journal of Economic Perspectives 4(2), 1990, 19-33.

19. Shefrin, H.\&Statman, M.,'Behavioral Capital Asset Pricing Theory', Journal of Financial and Quantitative Analysis, 29, 1994, 3,323-349.

20. Statman, M.,'Behavioral Finance: The Second Generation',CFA Institute Research Foundation, 2019

21. Trueman, B., 'A Theory of Noise Trading in Securities Markets', Journal of Finance, 1998, 43, 83-95.

22. Weber, M., 'Cash flow duration and the term structure of equity returns', Journal of Financial Economics, 128, 2018,486 - 503.

\section{About Our Author}

Rahul Verma is a Professor of Finance at the University of Houston-Downtown. The domain of his research is applied in nature and at the intersection of behavioral finance, investments and international finance. He empirically tests econometric models that combine global risk factors and investors' irrationality to scientifically explain and forecast international financial market movements. He is the recipient of the UHD Scholarly and Creativity Award, the Counselors of Real Estate's William Ballard Award, Faculty Advisor Recognition Award and Provosts' award for a leadership role in assessment initiatives. He teaches in the areas of Investments, Financial Planning, Managerial Finance and Financial Forecasting. 